\title{
Duas ou três coisas sobre a montagem das imagens em Jorge de Lima.
}

\section{Patricia Carmello, UFRJ}

Resumo: Este artigo parte da noção de montagem para analisar as Fotomontagens de Jorge de Lima, através de contribuições de autores da Psicanálise e da Teoria da Arte, bem como estudos sobre as vanguardas do início do século passado. Aqui, comparo a montagem de imagens artísticas a uma montagem surrealista de imagens de memória.

Palavras-chave: fotomontagens; palavra; imagem.

Tudo se levitando: esta felicidade não era impossível. Jorge de Lima

Talvez o reduzido número de estudos sobre as fotomontagens de Jorge de Lima, poeta brasileiro da primeira metade do século XX, deva-se não apenas ao caráter enigmático e pouco narrativo que as caracterizam positivamente como destoantes de sua obra poética, mas também ao que nestas se acentua em relação à sua poesia, que vem a ser o viés político agudo em relação a seu tempo, que se explicita e se condensa neste conjunto de imagens e versos que, por sua vez, permanecem como um desafio ainda atual à tarefa do crítico, situada antes na leitura do ponto onde as contradições se intensificam do que na interpretação de um suposto sentido unívoco da obra.

A primeira das fotomontagens de Jorge de Lima surge elaborada em conjunto com Murilo Mendes, como capa do livro de poemas do amigo, datado de 1938, e leva o mesmo título do trabalho, A Poesia em Pânico. As que compõem o restante do livro de Lima somam 41 fotomontagens acompanhadas de legendas ou versos, produzidas nos anos 30 e 40, de provável autoria única, reunidas e publicadas em 1943 sob o título A Pintura em Pânico, ${ }^{1}$ o que já desperta a curiosidade em torno de tal deslocamento de um pânico que passa da poesia à pintura.

A referência às vanguardas do início do século encontram-se no tom surrealista de composições como "O Julgamento do Tempo", no universo onírico de imagens como "As catacumbas marinhas contra o despotismo", em certa ironia dadaísta na colagem de um carneiro-falo adentrando a boca de um provável Roosevelt, em "Será revelado no final dos tempos". A curadora Simone Rodrigues, numa introdução ao catálogo da exposição de $2010^{2}$ que reproduz o livro de Lima, afirma que o autor brasileiro iniciou a elaboração das fotomontagens após ter lido La Fémme 100 Têtes, de Max Ernst.

A técnica 'em-si' da colagem de diversos materiais impressos - fotografias, gravuras, etc., remontadas e fotografadas - inicia-se com as colagens cubistas de Picasso e Braque do início do século, mas difere destas, pois não incorpora outros materiais não impressos, o que faz com que as primeiras aproximem a pintura da escultura, com a introdução de objetos reais no quadro. No entanto, Teodoro Rennó 
Assunção, em seu artigo sobre a obra de Lima, indaga sobre a possível presença de desenhos $^{3}$ nestas fotomontagens, o que nos leva a pensar se tal dúvida não seria desejada pelo autor, efeito da sobreposição de diferentes meios e técnicas que colocam em tensão uma concepção de arte purista e a apropriação da mídia pelo objeto artístico, realizada desde os ready-made de Duchamp (1913-17), que propõem um détournement do objeto, ao erigi-lo ao status artístico, liberando-o de sua função usual e mercadológica, ao mesmo tempo em que promove sua crítica.

A reapropriação de material da mídia, de fragmentos do cotidiano ou da cultura estabelecida impressos, remontados e colados, fotografados sob outra ordem e apresentação, constitui um primeiro traço das fotomontagens de Lima, e pode ser vista na imagem de A morte de Marat remontada sob a legenda "A Paz das Famílias", o que talvez lance luzes sobre o pânico apontado pelo título na pintura. Ao rearranjar uma imagem do clássico misturando-a aos mais diversos fragmentos, deformando-a e reinserindo-a numa ordem não mais evidente ou representativa, a montagem traz a necessária parada sobre esta noção que promove simultaneamente a destruição e a reconstrução do objeto, para indagar que crítica ela põe em questão.

Se, enquanto técnica cinematográfica, os primórdios da montagem situam-se nas montagens do cinema de Griffith (1908) e Eisenstein (1925); será o segundo montador e ao mesmo tempo um teórico da noção - que irá propô-la em termos de uma forma de apreensão do mundo, uma 'ordem de pensamento', como uma "montagem intelectual"4 baseada na dialética marxista, daí também chamá-la montagem dialética, na qual a resultante não apenas é pensada como algo diferente da simples soma das partes, mas como uma abertura a uma terceira possibilidade ${ }^{5}$, concepção presente ainda nos estudos sobre imagem de Roland Barthes ${ }^{6}$ na forma de um terceiro sentido da imagem não totalmente dado, não óbvio, mas a ser construído pela imaginação do observador ou leitor.

Para partir apenas do registro da técnica, a experiência de ambos os montadores estará no princípio das fotomontagens, na medida em que, ao recortar pela primeira vez duas imagens não contíguas e colá-las numa apresentação diferente da original, o cinema rompe sobretudo com a posição do espectador, de uma quarta-parede para um olhar deslocado, excêntrico, em movimento e imprescindível à apreensão da nova ordem dada pela montagem.

Assim, as fotomontagens são marcadas na origem tanto pelo cubismo das colagens de Picasso e Braque como pelo advento do cinema, da invenção das imagens em movimento ${ }^{7}$, como também pelos trabalhos de Heartfield e Schwitters, Hoch e Ernst, alguns nomes pioneiros que assumem propostas distintas, entretanto. A fotografia de Man Ray comparece não somente com imagens apropriadas, mas nos contrastes entre luz e sombra, branco e negro.

Contudo, logo se estabelece a questão ainda hoje em discussão em torno da montagem; isto é, o quanto ela revela do corte, da cesura, em uma palavra o quanto ela se revela como montagem; ou, por outro lado, encobre suas fissuras, costurando seus pedaços em busca de uma totalidade visual, narrativa ou discursiva. Não por acaso, este será um dos temas relevantes para Rennó Assunção em seu artigo sobre Jorge de Lima, quando indaga sobre uma possível totalidade ou autonomia narrativa entre as fotomontagens de Lima comparativamente às de Max Ernst. ${ }^{8}$ Acrescentamos, aqui, a indagação acerca de uma totalidade não necessariamente narrativa, mas poética, como a que propicia a reunião de poemas num livro, e que torna plausível a sua pertinência a uma determinada obra, e não à outra, e que parece estar em jogo nas fotomontagens de Lima. 


\section{A Montagem como Princípio}

Walter Benjamin, em "A Obra de Arte na Era da Reprodutibilidade Técnica"9 (texto de 1935), pensará o princípio de montagem a partir justamente de uma contraposição entre o cinema recém-surgido e a arte clássica, ao destacar o potencial que o primeiro adquire através do direito de escolha do montador, que corta, recorta e cola a partir de um sem-número de imagens, dentre as quais algumas irão compor uma constelação, uma (necessariamente) nova e parcial ordenação dada à obra. $\mathrm{O}$ montador é também comparado a um cirurgião - em contraposição ao xamã (este, por sua vez, comparado ao artista clássico) - por intervir diretamente no interior do material trabalhado, o fragmento, enquanto para a noção de arte ligada ao clássico, a dificuldade da reprodução mantinha a noção de aura, do aqui-agora da obra de arte intocável, o que lhe conferia um valor de ritual ou monumento que, por sua vez, associado aos valores de eternidade, unidade e totalidade, tornavam-na facilmente apropriáveis pelo fascismo.

O fascismo deve ser aqui compreendido não somente como o período datado por Hitler e Mussolini, mas no sentido que Michel Foucault dá ao termo: "o fascismo que está em todos nós, que martela nossos espíritos e condutas cotidianas, o fascismo que nos faz amar o poder, desejar esta coisa que nos domina e nos explora". ${ }^{10}$ Fascismo ao qual, no entanto, a noção de montagem se opõe, por seu caráter fragmentar que, ao reunir os pedaços, apela por novas ordens possíveis. Segundo Benjamin, a criação, ao partir da barbárie, pode vir a constituir a sua crítica, através da renúncia à tradição e o começar com os restos. Trata-se, pois, de "um conceito novo e positivo de barbárie. Pois o que resulta para o bárbaro dessa pobreza da experiência? Ela o impele a partir para a frente, a começar de novo, a contentar-se com pouco, a construir com pouco"11.

Este começar com os restos da barbárie constitui um modo de apreensão do tempo e da memória diferenciados, que subvertem a linearidade e a objetividade do pensamento. É o que vem acrescentar a noção de alegoria como reunião, colagem dos cacos, das ruínas da história; que surge, por sua vez, impregnada do pensamento do historiador da arte Aby Warburg, desenvolvido tanto em sua biblioteca como em seu Atlas Mnemosyne, como uma coleção de imagens ou restos de imagens, no caso da biblioteca, uma reordenação inusitada dos livros; ou uma mesa de montagem que, através de diferentes e inusitadas relações analógicas, propõe uma reconfiguração dos sentidos habituais, uma criação de novas possibilidades de sentido:

Ao modificar a ordem fazemos com que as imagens tomem uma posição. Uma mesa não se usa nem para estabelecer uma classificação definitiva, nem um inventário exaustivo, nem para catalogar de uma vez por todas - como um dicionário, um arquivo, ou uma enciclopédia - mas sim para recolher segmentos, trocos do parcelamento do mundo, respeitar sua multiplicidade, sua heterogeneidade. E para outorgar legibilidade às relações postas em evidência. ${ }^{12}$

É neste ponto que podemos afirmar que o pensamento analógico colocado em cena na montagem desafia a lógica, a linearidade, a cronologia do tempo e a objetividade da memória; na medida em que a remontagem do tempo, ao propor novas e insuspeitas comparações entre as imagens, rompe com todos aqueles pressupostos 
tradicionais da concepção de memória e tempo, reinserindo no tempo a sua espessura, a sua densidade. Pois, quando Benjamin afirma que a "verdadeira imagem do passado perpassa veloz"13 - trata-se de uma imagem esquecida e vencida, a ser redimida ou emancipada - o materialista histórico põe em evidência um tempo que coloca o passado em relação com o presente (o agora da possibilidade de conhecimento, de onde o historiador volta seu olhar ao passado) ${ }^{14}$ e o futuro.

A concepção de memória feita de um tempo em camadas encontra ressonância nas formulações sobre o Inconsciente de Freud, para quem o trabalho de análise, de rememoração, é comparado às escavações de ruínas: "Seu trabalho de construção, ou, se se preferir, de reconstrução, assemelha-se muito à escavação, feita por um arqueólogo, de alguma morada que foi destruída e soterrada, ou de algum antigo edifício". ${ }^{15}$

Para a psicanálise, não há uma sequência ou seta única do tempo, na direção passado-presente-futuro, mas "a memória se desdobra em vários tempos". ${ }^{16}$ Assim, os tempos podem coabitar ou fundir-se numa mesma espessura, de acordo com a noção de nachträglichkeit, segundo a qual o passado é determinado pelo presente: é sempre do agora que me volto para um passado nunca totalmente recuperado ou integrado na lembrança, que produz um resto a incidir sobre o futuro numa nova volta ou dobra do tempo, através da qual a rememoração rompe com a cronologia.

Para Freud, o caráter intemporal dos processos inconscientes, a sua não-adequação à ordenação cronológica, ${ }^{17}$ bem como a mobilidade de suas imagens de combinaremse livremente são descritos como características que definem a própria noção de inconsciente, que desconhece a noção de tempo. A referência ao tempo seria dada só depois, pelo consciente, o que assinala sua insubmissão ao tempo cronológico e seu parentesco com estas formulações sobre a montagem nas obras de arte. Não por acaso, é à montagem e ao surrealismo que Lacan recorre no seminário de 1964 como termo de comparação em sua tentativa de situar a pulsão freudiana como distinta do instinto, na forma com que ela contorna o objeto e o inscreve na memória como objeto a ser buscado, tornado imagem, imaginado; mas nunca numa relação de satisfação ou completude:

A montagem da pulsão é uma montagem que, de saída, se apresenta como não tendo nem pé nem cabeça - no sentido em que se fala de montagem numa colagem surrealista. [...] creio que a imagem que nos vem mostraria a marcha de um dínamo acoplado na tomada de gás, de onde sai uma pena de pavão que vem fazer cócegas no ventre de uma bela mulher que lá está incluída para a beleza da coisa. ${ }^{18}$

Pois este jogo é lido, aqui, tal como Benjamin apropriou-se do fort-da apresentado por Freud em "Além do Princípio do Prazer" 19 para falar não somente da criação de imagens da memória, observada por Freud no gesto de seu neto ao jogar o carretel; mas do processo de criação artística, como algo que diz respeito a um movimento de idas e vindas, ausências e presenças, na construção de uma imagem - conceito mais tarde retomado pela metáfora do pêndulo de Paul Valéry, ${ }^{20}$ onde novamente a ausência tem lugar fundamental.

O movimento se apresenta como aspecto-chave; pois, se a criação de uma imagem só se produz numa obra de perda, a experiência do vazio só vale na medida em que promove algum movimento em direção ao desejo; isto é, deve ser vista como um 
processo, sendo somente "reveladora por ser dialética (...) mostrando o objeto como perda, mas ultrapassando também a privação em dialética do desejo". ${ }^{21}$

\section{O Poeta Trabalha}

Se o esquecimento revela-se para a imaginação como dimensão essencial, a montagem não se detém no elogio da falta, da impossibilidade, opondo a paralisia ao movimento, a ruína ao gesto do montador ou colecionador que transfigura as coisas, gesto repetido por Jorge de Lima ao numerar e assinar os únicos 250 exemplares das suas fotomontagens:

O interior é o lugar do refúgio da arte. O colecionador é o verdadeiro ocupante do interior. Ele transfigura os objetos para torná-los coisa sua. Seu papel é o de Sísifo: ao possuir as coisas, deve despojá-las de seu caráter de mercadorias. (...) O colecionador se imagina não só num mundo longínquo ou passado, mas, ao mesmo tempo, num mundo melhor (...) onde as coisas estão dispensadas da sobrecarga de serem úteis. ${ }^{22}$

O colecionador é comparável, ainda, ao poeta enunciado por Benjamin como catador do lixo que a cidade jogou fora, que a partir dele pode realizar sua crítica; aquele que propõe uma recriação do real a partir dos pedaços, dos resíduos da história. Daí deriva a viabilidade da leitura política de Murilo Mendes sobre as fotomontagens de Jorge de Lima:

A foto-montagem implica uma desforra, uma vingança contra a restrição de uma ordem do conhecimento. Antecipa o ciclo de metamorfoses em que o homem, por uma operação de síntese da sua inteligência, talvez possa destruir e construir ao mesmo tempo. ${ }^{23}$

Num autor já descrito pelo historiador da literatura Alfredo Bosi como "um mestre de linguagem", ${ }^{24}$ as palavras operam cortes analíticos nas imagens - à imagem do pombo branco saído de telhados escuros segue-se a legenda: "O anunciador da catástrofe" - assinalando uma paz forjada. Como intervenções analíticas, as palavras colocam tudo em movimento, retirando as imagens do recalque, dando nome e origem à produção de novas imagens. Como na epígrafe deste artigo, fazem referência a uma camada do tempo passado que é reinserida no presente, a um tempo que faz tudo levitar, no qual a felicidade não era de todo impossível...

A relação entre palavra e imagem poderia ser pensada, ainda, a partir da noção de 'etapa' formulada por Roland Barthes; ${ }^{25}$ pois, mais do que uma ancoragem da imagem pelo texto; aqui, a relação se dá num jogo de forças complementar, no qual a palavra insere, acrescenta sentidos não contidos na imagem. As palavras surgem como legendas para dizer o que a imagem, por si, não revela, mas pede para ser nomeado; o que possibilita, ainda de acordo com a citação utilizada por Benjamin: "ler o que nunca foi escrito". ${ }^{26}$ A mesma indissociabilidade entre palavra e imagem é apontada por Eisenstein, ao afirmar como 'matriz' de sua montagem de imagens, a montagem literária encontrada no texto de Flaubert. ${ }^{27}$

Jorge de Lima (1895-1953) viveu na primeira metade do século XX, contexto que sugere a leitura de referências ao nazi-fascismo das duas Grandes Guerras mundiais, além da ditadura da Era Vargas no Brasil, iniciada nos anos 30 e marcada pela 
simpatia inicial ao governo alemão. Além disso, a partir dos anos 20, o país assiste ao surgimento do cinema falado, o que desperta o interesse do Estado pelo incentivo à produção nacional; bem como, após a década de 40, a crescente valorização da propaganda - cuja linguagem traz em si novas relações entre texto e imagem - como veículo cultural privilegiado. ${ }^{28}$

A fotomontagem que dá título ao livro de Murilo, 'Poesia em Pânico', pode constituir possível referência a este cenário. Porém, em duas outras imagens, a poesia resiste em sua potência crítica, no único verso que se repete pelo livro: " $A$ poesia abandona a ciência à sua própria sorte". ${ }^{29} \mathrm{Na}$ primeira, há o torso mutilado de uma Vênus de Milo e um par de mãos acorrentadas, num porto sombrio. Na segunda, um homem de olhos fechados com um violino volta às costas para um suposto rei ou figura religiosa e para outro homem, torturado numa engrenagem que lembra a Inquisição.

Tirania e despotismo ameaçam imperar num universo de imagens sombrias, no qual a arte e a poesia vem interceder; destruindo-o, cortando-o e reconstruindo-o em outra forma, outra ordem, conferindo outra legibilidade às imagens, retirando-lhes o caráter pretensamente totalitário e abrindo-as para novas imagens. As imagens comparecem em permanente tensão, fruto da montagem dialética de Benjamin, Freud e Eisenstein: bem e mal, Caim e Abel, surgem de mãos dadas. "Surgiram forças eternas para lutar contra forças idênticas" 30 mostra um homem ao longe caminhando em meio a uma montanha na qual se enterra um pedaço de cristo crucificado.

Imagens religiosas, planetas, hecatombes, seres alados, constelações, guerras, levam a pensar que o que se trata nas fotomontagens de Lima seria um projeto de reconstrução da história a partir de suas ruínas, no qual a poesia intervém, como um julgamento do tempo - outra de suas legendas libertárias e enigmáticas - abrindo novas temporalidades no interior do próprio tempo.

A religiosidade cristã, entretanto, contrasta com a leitura dialética da história, quando no conflito entre a totalidade e a fragmentação, surge um braço gigante com desenhos romanos acima de uma multidão, numa aldeia, ao qual se opõe, de outro lado, outro braço de onde pende um enforcado, e lê-se: "A poesia de uns depende da asfixia de outros". O que logo nos faz lembrar que o conhecido místico é o mesmo autor de versos de resistência como "Há sempre um copo de mar/ para um homem navegar", ${ }^{31}$ ou da provocação explícita nos pouco comentados Poemas Negros: "Há ainda muita coisa a recalcar". ${ }^{32} \mathrm{O}$ mesmo parece ocorrer com a fotomontagem 'América versus Europa', composta de um corpo feminino de cabeça não-humana acuado diante de duas cabeças sem corpo, se evocamos os versos de 1927 de " $A$ Minha América": "Roosevelt rindo para a mortel A Bíblia rindo para o mundo/ Tio Sam rindo para tudo!" 33

\begin{abstract}
This article starts out from the notion of montage to analyze Jorge de Lima's photomontages through contributions of Psychoanalysis and Art Theory, as well as studies on the vanguards of beginning of the century. Here, I compare the montage of artistic images with a surrealist montage of memory images.
\end{abstract}

Keywords: photomontage; word; image. 


\section{ANEXO:}

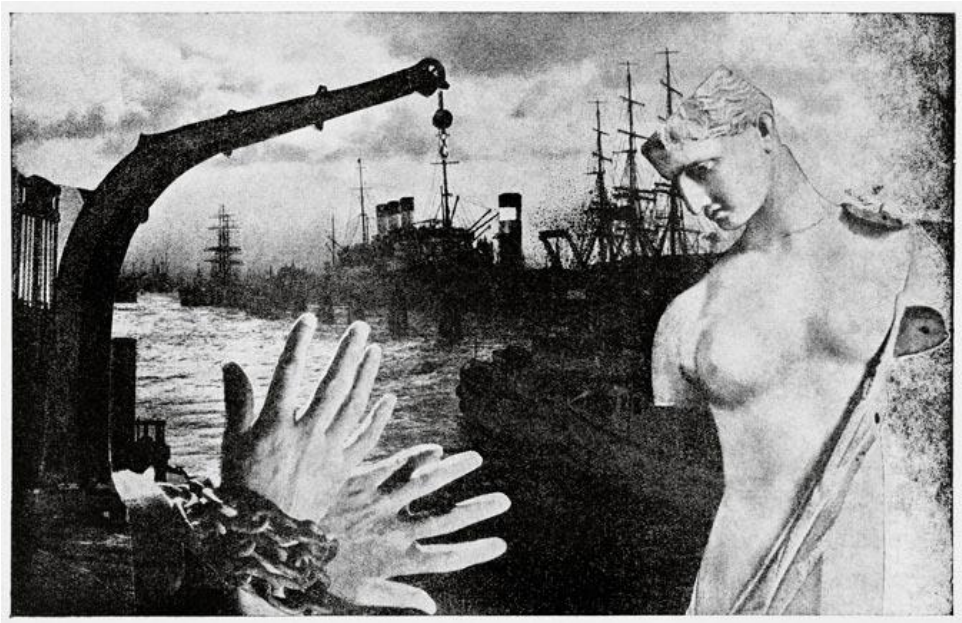

Fonte: A Pintura em Pânico, catálogo da exposição, maio de 2010, 136p.

\section{Referências Bibliográficas:}

A pintura em pânico: Fotomontagens: Jorge de Lima. Catálogo da exposição (com a íntegra do livro homônimo de Jorge de Lima, de 1943), maio de 2010, 136p.

AMIEL, Vincent. Estética da Montagem. Lisboa: Edições Texto e Grafia Ltda, 2007.

ASSUNÇÃO, Teodoro Rennó. Fotomontagem e Colagem Poética em Jorge de Lima. O Eixo e a Roda: v. 9/10, 2003/2004, p. 53-73. Disponível em: <http://www.letras.ufmg.br/poslit>. Acesso em março de 2011.

BARTHES, R. O Óbvio e o Obtuso. Lisboa, Edições 70, 2009.

BENJAMIN, Walter. Magia e técnica, arte e política. Obras escolhidas I. São Paulo: Brasiliense, 2 ed, 1986.

. Alegoria e Drama Barroco. In: Documentos da cultura, documentos de barbárie. São Paulo: Cultrix, 1986a, p. 17-39.

. Paris: capital do século XIX. In: COSTA LIMA, Luis. (Org.). Teoria da

Literatura em suas Fontes. Rio de Janeiro: Francisco Alves, v. 2, 1983, p. 134-149.

. Paris: capitale du XIXe siècle. Paris: Editions du Cerf, 1993.

. Passagens. Belo Horizonte/ São Paulo: Editora UFMG/Imprensa Oficial, 2006.

. Écrits Français. Paris: Folio-Gallimard, 1991. 
BOSI, Alfredo. História Concisa da Literatura Brasileira. São Paulo: Cultrix, 1978.

DIDI-HUBERMAN, Georges. O que vemos, o que nos olha. São Paulo: Ed.34, 1988.

. Atlas. Une arquéologie du savoir visuel. Seminário promovido pela L’École des Hautes Études en Sciences Sociales. Paris: Institut Nacional d'Histoire de l'Art, outubro de 2009 a maio de 2010.

Atlas: como levar o mundo nas costas? Sopro, n. 41, dezembro de 2010. Disponível em <http://www.culturaebarbarie.org/sopro/n41.html >. Acesso em janeiro de 2011.

EISENSTEIN, Sergei. A Forma do Filme. Rio de Janeiro: Jorge Zahar Ed., 2002.

FOUCAULT, Michel. Introdução à vida não-fascista. Preface. In: DELEUZE, Gilles; GUATTARI, Félix. Anti-Oedipus: Capitalism and Schizophrenia. Trad. Wanderson Flor do Nascimento. New York: Viking Press, 1977, p. XI-XIV.

FREUD, Sigmund. “Além do Princípio do Prazer”. In: ESB, v. XVIII. Rio de Janeiro: Imago, 1976, p. 17-85. 289-304.

Construções em Análise. In: ESB, v. XXIII. Rio de Janeiro: Imago. 1975, p.

Carta 52. In: Edição Standard Brasileira das obras completas de Freud, v. I. Rio de Janeiro: Imago, 1988, p. 281-287.

. O Inconsciente. In: ESB, v. XIV. Rio de Janeiro: Imago, 1988a, p. 165-222.

LACAN, Jacques. O Seminário, livro 1: os escritos técnicos de Freud. Rio de Janeiro: Jorge Zahar Editor, 1986.

. O Seminário, livro 11. Rio de Janeiro: Jorge Zahar Editor, 2008.

LIMA, Jorge de. Poesia Completa. Rio de Janeiro: Nova Aguilar, 1997.

LÖWY, Michel. Walter Benjamin: aviso de incêndio: uma leitura das teses "Sobre o Conceito de História”. São Paulo: Boitempo, 2005.

SOUZA, Carlos Roberto. Cinema em Tempos de Capanema. In: BONEMY, Helena. (Org.). Constituição Capanema. Rio de Janeiro: ED. FGV; Bragança Paulista (SP): Ed. Universidade São Francisco, 2001, p. 154-182.

VALÉRY, Paul. Variedades. São Paulo: Iluminuras, 1999.

VELloso, Mônica. Cultura e Poder Político. In: Estado Novo: Ideologia e Poder. OLIVEIRA, Lúcia Lippi et al (Org.). Rio de Janeiro: Zahar Editores, 1982, p. 71-108.

\section{Notas}

${ }^{1}$ A PINTURA EM PÂNICO: Fotomontagens: Jorge de Lima.

${ }^{2}$ Op. Cit., p.9.

${ }^{3}$ ASSUNÇÃO. Fotomontagem e Colagem Poética em Jorge de Lima. 


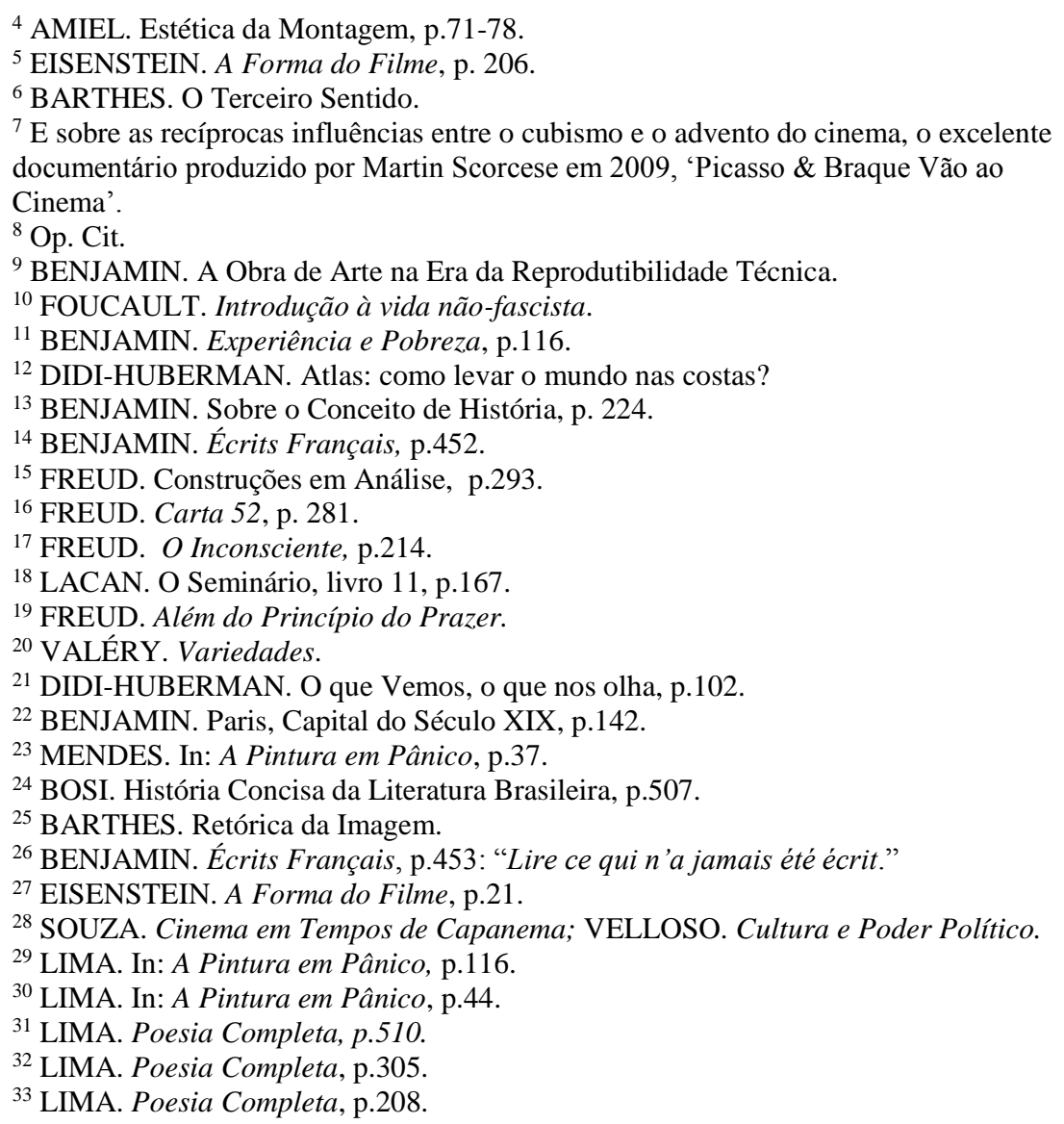

